\title{
The use of augmented toys to facilitate play in school-aged children with visual impairments
}

\author{
Suzanne H. Verver*, Mathijs P.J. Vervloed, Bert Steenbergen \\ Behavioural Science Institute, Radboud University, Montessorilaan 3, 6525 HR, Nijmegen, the Netherlands
}

\section{A R T I C L E I N F O}

No. of reviews completed 2

Keywords:

Children with visual impairments

augmented toys

social play

cognitive play

joint attention

\begin{abstract}
A B S T R A C T
Background: Children with visual impairments (VIs) face challenges in social play activities, which limits their opportunities to practice social skills.

Aims: We investigated whether augmented toys were effective to facilitate play in 52 children with VIs who attended special schools for students with visual impairments and blindness.

Methods and procedures: 52 children with VIs (mean age: 9.22 years, SD $=2.07$ ) played three times with both an augmented and a non-augmented toy. A Playmobil ${ }^{\circledR}$ knight's castle was augmented with Radio Frequency Identification (RFID) technology, such that each play figure produced audio feedback during play. The RFID-technology could be activated and deactivated. Social and cognitive aspects of play were coded from video and data were analyzed using multilevel logistics.

Outcomes and results: Children showed less disengagement and more parallel play, but less cooperative play when they used the augmented versus the non-augmented castle. This pattern persisted after repeated play sessions with both toys.

Conclusions: The addition of sounds to physical toys increased shared attention between children with VIs during the exploration of play materials, yet it interfered with social interaction during peer play.
\end{abstract}

\section{What this paper adds?}

Play and social interaction difficulties in young children with visual impairments (VIs) have often been reported, emphasizing the need for additional support during peer play in particular. However, most studies on this topic involved small numbers of participants and lacked controlled experimental designs. The present study contributes to the current knowledge about play behavior of schoolaged children with VIs by performing multiple observations of play behavior in a relatively large group of children with VIs. We investigated possibilities for sound augmentation of play materials to facilitate peer play using a crossover repeated measures design. Auditory cues are often assumed to compensate for visual cues that people with VIs miss out on. This is the first study that shows that sound augmentation can facilitate shared attention between children with VIs, but interferes with actual peer play at the same time. Furthermore, our findings indicate that the profoundness of the visual impairment is unrelated to social play of children with VIs.

\section{Introduction}

Play is an important context through which children acquire various cognitive, language, and social abilities (Bergen, 2002;

\footnotetext{
*Corresponding author at: Behavioural Science Institute, Radboud University Nijmegen, PO Box 9104, 6525 HE, Nijmegen, the Netherlands. E-mail addresses: s.verver@pwo.ru.nl (S.H. Verver), m.vervloed@pwo.ru.nl (M.P.J. Vervloed), b.steenbergen@pwo.ru.nl (B. Steenbergen).
} 
Lillard et al., 2013). Some even consider play to be a separate developmental domain (Lifter, Foster-Sanda et al., 2011; Lifter, Mason et al., 2011). Children with visual impairments (VIs) are challenged to benefit from play in similar ways as sighted children due to difficulties with peer interaction and necessary behavioral adaptations to the visual impairment (Celeste, 2006; Fraiberg, 1977; Hestenes \& Carroll, 2000; Hughes, Dote-Kwan, \& Dolendo, 1998; Preisler, 1993; Rettig, 1994; Sacks \& Kekelis, 1992). Typically developing young children are known to carefully observe and imitate their caregivers and peers. In this way social aspects of play (e.g., the level of social involvement) evolve from solitary, to parallel, and finally to cooperative play, where children actively interact and pursue shared goals within the play context (Howes \& Matheson, 1992; Parten, 1932).Whereas sighted children spontaneously imitate behavior and share experiences and non-verbal interactions with adults and peers during play, children who are blind or visually impaired are challenged to engage in these joint attention behaviors (Mundy \& Sigman, 1989; Mundy, Sigman, \& Kasari, 1990). They experience an inability to respond appropriately to non-verbal interaction bids of others, which leads to difficulties when entering or keeping up with peer play (Warren, 1994; Wolfberg \& Schuler, 1993). Children with VIs tend to play alone often at ages when cooperative play is considered common in sighted children (Celeste, 2006; Erwin, 1993; Howes \& Matheson, 1992; Sacks \& Kekelis, 1992; Skellenger, Rosenblum, \& Jager, 1997; Sleeuwenhoek, Boter, \& Vermeer, 1995; Troster \& Brambring, 1994). Especially children with blindness are at risk for peer rejection, because they show less distinguishable facial expressions to convey emotions and intentions (Galati, Miceli, \& Sini, 2001; Roch-Levecq, 2006) and frequently demonstrate awkward behaviors such as mannerisms $^{1}$, often perceived as symptoms of autism (Roe \& Webster, 2002). Although adults can create positive social experiences for children with VIs by assisting them during peer play (Perez-Pereira \& Conti-Ramsden, 2013), adult support has also been found to induce passiveness in children with VIs and feelings of dependency and helplessness (Roe \& Webster, 2002).

Social aspects of play are intertwined with the development of cognitive aspects of play (i.e., the manner in which a child plays and uses toys). Cognitive play develops from simple object manipulation to the appropriate use of toy functions and to complex forms of symbolic or pretend play (Belsky \& Most, 1981; Howes \& Matheson, 1992; Rubin, Maioni, \& Hornung, 1976). This increase in play complexity occurs parallel to the developmental transition from solitary to social play (Pellegrini, 1982; Rubin et al., 1976). Especially symbolic play has many social elements and is often demonstrated during peer play (Howes \& Matheson, 1992). It is positively correlated with aspects of early language development (Elias \& Berk, 2002; Lewis, Boucher, Lupton, \& Watson, 2000; Pizzo \& Bruce, 2010), Theory of Mind development (Astington \& Jenkins, 1995; Lillard, 1998; Youngblade \& Dunn, 1995), and social skills development (Doyle \& Connolly, 1989; Doyle, Doehring, Tessier, de Lorimier, \& Shapiro, 1992; Howes, Unger, \& Matheson, 1992). However, in preschoolers with VIs the transfer from object manipulation to functional and symbolic play can be delayed up to two years compared to their sighted peers (Fraiberg, 1977; Hughes et al., 1998; Lewis, Norgate, Collis, \& Reynolds, 2000; Rogers \& Puchalski, 1984; Troster \& Brambring, 1994). The lack of eyesight makes it difficult for children with VIs to form concepts of objects and to understand how toys can be used according to their functions, especially if a multiplicity of objects is available (Lewis, Norgate et al., 2000; Perez-Pereira \& Conti-Ramsden, 2013; Recchia, 1997). Specifically children with congenital blindness tend to use a limited amount of toys and their play can be of a repetitive or stereotypical nature (Brown, Hobson, Lee, \& Stevenson, 1997; Rettig, 1994; Skellenger et al., 1997). A study of Bishop, Hobson, and Lee (2005) showed that difficulties with the use of symbolic play were still present in 5-to-9 year old children with congenital blindness, but only for those who also had low social competence and autistic features according to their teachers. This suggests that play difficulties can be persistent into middle childhood in some children with VIs, limiting their possibilities to practice social skills and roles that are necessary in interaction, and to form and maintain friendships with peers, a fundamental developmental task for children (Guralnick, Connor, \& Hammond, 1995). For example, social support is known to predict wellbeing in adolescents with VIs (Huurre, Komulainen, \& Aro, 1996; Kef \& Deković, 2004). Several studies showed that adolescents with VIs received less social support from parents or peers than sighted adolescents. Whereas adolescents with VIs mostly received parental support, it was peer support that predicted their wellbeing. The researchers concluded that adolescents with VIs desired to fit in and experienced a need for independence from their parents (Huurre et al., 1996; Kef \& Deković, 2004). It therefore seems of vital importance that peer play is facilitated in children with VIs without the need for adult help.

An alternative for adult support is the use of augmented toys to support peer play. This turned out to be successful in children with autism, who also experience difficulties to share attention and objects in interaction with peers (Farr, Yuill, \& Raffle, 2010; Farr, Yuill, \& Hinske, 2012). Augmented toys consist of physical play materials enhanced with technology, creating possibilities to add new features to toys. They are designed to offer new play experiences to children that stimulate engagement and motivation, but also to promote playful learning and collaborative exploration (Hinske, Lampe, Yuill, Price, \& Langheinrich, 2009). In their study, Farr et al. (2012) used a Playmobil ${ }^{\circledR}$ castle that was augmented with radio-frequency identification (RFID) tags, enabling play figures to produce pre-programmed sounds when put on specific locations in the castle (Farr et al., 2012; Lampe \& Hinske, 2007). Results indicated that triads of children with autism demonstrated less solitary play while using the augmented knight's castle compared to the condition in which they played with a normal knight's castle. Participants also used more ways to get from solitary to social play (Farr et al., 2012). When children with autism used Topobo, a construction toy augmented with programmable movement, they demonstrated less disengagement and solitary play and more parallel play than while using Lego ${ }^{\circledR}$ (Farr et al., 2010). This suggests that the addition of sounds or movement facilitates shared play experiences and may support more pathways to social interaction (Farr et al., 2012), at least in children with autism.

The present study examined the effect of augmented toys on the play behavior of children with VIs. The following research question was formulated: What effect do augmented toys with sounds have on the social and cognitive play behavior of dyads of children with VIs? Similar to findings in children with autism, we hypothesized that enriching toys with auditory cues will facilitate

\footnotetext{
${ }^{1}$ Mannerisms or stereotypical behaviors in children with blindness are often referred to as blindisms (Leonhardt, 1990).
} 
shared experiences and joint attention in children with VIs. Joint attention is a prerequisite for social interaction to occur (Mundy \& Sigman, 2015). In the absence of vision, sounds and music are expected to increase a child's attention and awareness of his/her play partner's actions and therefore substitute, at least partially, non-verbal behavior as the indicator of the interaction partner's focus of attention (Robb, 2003). Sounds are therefore expected to act as a compensatory mechanism for the lack of vision. Playmobil ${ }^{\circledR}$ toys are being designed primarily to elicit functional and symbolic play, making them suitable for both solitary use as well as peer play. However, similar to the majority of toys, Playmobil ${ }^{\circledast}$ objects are small and visually but not tactually stimulating, making them less interesting for children with VIs to play with (Troster \& Brambring, 1994). Sound augmentation creates opportunities to facilitate the identification of play figures or locations within the Playmobil ${ }^{\circledast}$ knight's castle, and adds play suggestions that are related to specific toys. We therefore hypothesized that, compared to the normal knight's castle, playing with the augmented castle will facilitate both social and cognitive play in dyads of children with VIs. Children with VIs need a substantial amount of time to manipulate objects in order to familiarize themselves with the toys and to be able to use them in functional or symbolic play. It is therefore anticipated that multiple play sessions with an augmented toy are needed to facilitate more complex forms of both cognitive and social play. In addition, multiple play sessions provide the opportunity to distinguish between long lasting or temporary effects of adaptive behaviors. Participants in the current study thus played multiple times with the augmented knight's castle and multiple times with a normal castle.

\section{Method}

\subsection{Participants}

Parents of 153 school-aged children with a VI as their primary disability received a letter of informed consent through two national organizations for people with a visual impairment (Royal Dutch Visio and Bartiméus). All children visited special elementary education for visual impairment and blindness and were approached if they met the following criteria: a) between 4 and 12 years of age, b) an IQ-score above 70, c) no hearing impairment, d) able to play on the floor with small objects, e) Dutch as the first language. A total of 61 children (response rate: 40\%) were granted permission to participate in our study. Participants were then randomly assigned to dyads based on age (maximum age difference between two children of 2.5 years) and the location of the special school they attended. Three children had to be excluded because it was impossible to form a dyad based on the formerly mentioned criteria. Three dyads refused further participation during the study because they did not like the play materials or they disliked their playmate.

The total sample consisted of 52 children (26 dyads; $25.3 \%$ girls) with a mean age of 9.22 years $(S D=2.07)$. Dyads were divided into three different age groups: 4 - to 7-year-olds $(n=4)$, 7 - to 10 -year-olds $(n=13)$, and 10- to 13 -year-olds $(n=9)$. There were 17 boys' dyads, 5 girls' dyads and 4 mixed dyads. The mean visual acuity of the participants was 21/100 or .21 (SD = .20). Based on criteria of the World Health Organization (Revision 2006), the profoundness of the participants' visual impairment could be classified into three categories: a moderate VI (visual acuity between $6 / 18$ and 6/60; $n=34$ ), a severe VI (visual acuity between $6 / 60$ and 3 / $60 ; n=9$ ) and blindness (visual acuity $<3 / 60 ; n=9$; ICD-10, 2015). The participants' visual impairments were caused by a variety of different etiologies that often co-occurred with each other. Out of the 28 different diagnoses, a cortical visual impairment (CVI; $n$ $=8)$, Leber's amaurosis $(n=6)$ and ocular albinism $(n=5)$ were the most common; nystagmus most frequently co-occurred alongside other etiologies $(n=10)$. The Ethical Comity of the faculty of Social Sciences of the Radboud University gave ethical approval for the present study (file number: ECSW-2017-040).

\subsection{Procedure}

The study took place at six different special schools for children with a visual impairment and blindness. A counterbalanced crossover repeated measures design with six play sessions was used. Dyads were randomly assigned to start playing in either the augmented condition (AC; 42.4\%) or normal condition (NC; 57.6\%). During the same week, dyads played in both the AC and NC with at least two days in between both sessions, meaning that participants were their own controls. This was repeated two times with test weeks interspersed by one week. Each play session lasted thirty minutes. At the beginning of the first play session all the play figures and objects belonging to the castle were introduced to the children before the actual play session began. This warm up session was included to prevent biased results due to exploratory or adaptive behaviors. A standardized instruction and demonstration of how play figures could produce sounds was given to all dyads before the start of the augmented condition. A researcher was present during the play sessions for video registration, in the meanwhile keeping the amount of interaction between her and the children to a minimum.

In order to observe social aspects of play behavior, 15-minute samples were randomly selected from the 30-minute sessions to rule out possible warm up effects and effects of fatigue and attention loss during the session. Start times of 15-minute fragments were randomly selected between 120 and 720 seconds, as the first two minutes of each video-fragment were excluded from coding to allow children to adapt to the experimental setting (e.g., to the video cameras). The first 10 minutes of these 15-minute fragments were then used to observe cognitive aspects of play. Coding was executed by research-assistants who received intensive observational training and who were blind for the research objectives. At first it was attempted to code events instead of intervals, but it appeared to be too difficult to reach sufficient inter-rater reliability $(k>.80$; Cohen, 1968) due to frequent changes between different types of play. Therefore, the occurrences of one of four possible social aspects and one of seven cognitive aspects of play were coded in consecutive 10-second intervals, using Observer XT version 11.5 software of Noldus. If more than one of the social or cognitive play behaviors was 


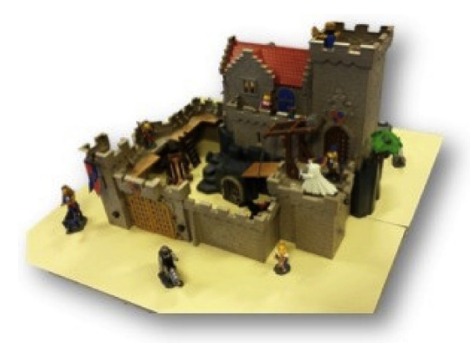

Fig. 1. Augmented Knights Castle.

demonstrated during a 10-second interval, the one that lasted the longest was coded. This resulted in 91 (for social aspects) or 61 codes (for cognitive aspects) per video-fragment, for a total amount of 143 videos.

\subsection{Instruments}

\subsubsection{Augmented Knight's Castle}

An augmented castle similar to that of Lampe and Hinske (2007) was used. The augmented castle consisted of a plywood base and a Playmobil ${ }^{\circledast}$ knight's castle, in which RFID-readers were integrated at five different locations in either the base or the castle (tower, courtyard, gate, cellar and in front of the cellar). Thirteen play figures were equipped with RFID-tags that were detected when held at a distance of about 2 centimeters from the readers. The plywood base contained a microprocessor that controlled the RFID-readers when connected to a laptop via USB (see: Figs. 1 and 2). Registration of a tag was followed immediately by sound feedback from a speaker inside the base. The sounds varied as a function of both location as well as play figure, with a total of 75 different sounds. Psychopy software was used to control and register the sounds. At three locations (tower, courtyard and gate) play figures not only produced sounds when they entered the location, but also when they stood on the location for a minimum of 8 seconds. Similar to the study of Farr et al. (2012), three different kinds of sounds were used: identification sounds (e.g., 'I am the king'), theme sounds (e.g., Medieval music, bird sounds), and play proposals (e.g., 'The castle is under attack!'). A log file of all registrations of time, place and play figure was automatically saved after each play session.

\subsubsection{Social and cognitive play observation scales}

In order to observe social aspects of play, a mutually exclusive observational system was used that was based on the social play scale of Parten (1932); Wolfberg and Schuler (1993) and Farr et al. (2012). For cognitive aspects of play, a mutually exclusive observational system was used based on the play observation schemes of Belsky and Most (1981); Wolfberg and Schuler (1993) and the S.O.S.-Blind scale of Van den Broek, Moleman, and Hellendoorn (2005). See Table 1 for precise definitions of observational categories. In order to obtain sufficient inter-rater reliability, the observers were trained using eight video recordings of twenty minutes each from a pilot study. Children in this pilot study did not participate in the current study. Inter-rater reliability regarding frequency and sequence of the codes yielded a Cohen's kappa of .82 for the overall social play scale and .86 for the cognitive play scale. In addition, inter-rater reliability on a coding sample of $20 \%$ of this study's videos was sufficiently high for the social play scale $(k=.82$ and cognitive play scale $(k=.79)$.

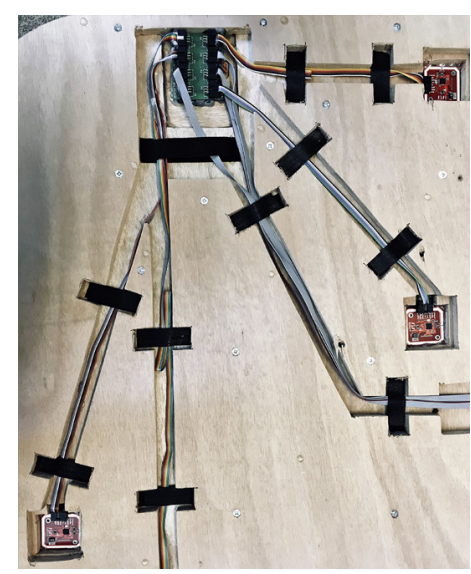

Fig. 2. RFID- readers and microprocessor inside the base. 
Table 1

Social and cognitive play observation scales

\begin{tabular}{|c|c|}
\hline Social aspects of play & Cognitive aspects of play \\
\hline Disengagement & Manipulative play \\
\hline $\begin{array}{l}\text { The child is not focused on playing but looks around or talks about subjects } \\
\text { unrelated to play. }\end{array}$ & $\begin{array}{l}\text { 1) Object exploration, 2) sound exploration by putting play figures on } \\
\text { readers, 3) listening to or observing playmate during play. }\end{array}$ \\
\hline Solitary play & Functional play \\
\hline $\begin{array}{l}\text { The child plays alone. He/she seems unaware of the playmate or may } \\
\text { deliberately choose not to engage with the playmate. }\end{array}$ & $\begin{array}{l}\text { Using play materials in ways they are supposed to be used (shooting a rock } \\
\text { with the catapult; opening doors in the castle). }\end{array}$ \\
\hline Parallel play & Functional play with pretense \\
\hline $\begin{array}{l}\text { Children are playing in close proximity of each other, look or smile at each } \\
\text { other, or imitate each other's play. There is no clear intention to play } \\
\text { together. }\end{array}$ & $\begin{array}{l}\text { Adding symbolic meaning to objects that is highly related to the function of } \\
\text { play materials (e.g., the swords of two knights are ticking together). }\end{array}$ \\
\hline Cooperative play & Symbolic play \\
\hline $\begin{array}{l}\text { Children are involved with each other and play together. They talk about } \\
\text { play-related subjects, help each other, and actively try to reach shared } \\
\text { goals during play. }\end{array}$ & $\begin{array}{l}\text { 1) An object is used as if it was another object, 2) pretend play where } \\
\text { characteristics or roles are added to play figures and meaningful actions are } \\
\text { carried out. } \\
\text { Games with rules } \\
\text { A game is made up that has clear rules or a specific structure that is known to } \\
\text { both children in a dyad. } \\
\text { Sensopathic play } \\
\text { Touching of objects or materials because this gives the child a pleasant } \\
\text { tactual experience. } \\
\text { Repetitive play } \\
\text { Play that has a rigid nature and does not belong in the context of other forms } \\
\text { of play. }\end{array}$ \\
\hline
\end{tabular}

Note. A category was coded when the concurrent behavior was dominant within a 10-second interval.

\subsection{Statistical analyses}

This is a study with a quantitative, quasi-experimental design that investigated differences regarding social and cognitive play behaviors between two play conditions and during three different measurement weeks. Multilevel logistic regression (MLR) was used to analyze data. MLR predicts proportions of whether or not an event will occur while dealing with dependency in the data (Sommet \& Morselli, 2017), in this case the nesting of participants within dyads and the autocorrelation between repeated measurements. The dependent variables in this study (i.e., the play behaviors) consisted of non-negative counts ranging from 0 (the play behavior did not occur) to a maximum of 61 or 91 . MLR is suitable for the analysis of these data with a binomial distribution.

Data were analyzed in SPSS version 23 by means of generalized linear mixed models with dyad and individual as random intercept variables and relative frequency of each social and cognitive aspect of play as dependent variables. Before the MLR was executed, total social play frequencies were corrected for the number of times that participants were unable to play together due to external factors.

Firstly, the occurrences of each social and cognitive play behavior relative to total possible play behaviors (i.e., the number of successes) were entered in the MLR model, together with the random intercept variables. Secondly, dummy variables were created to model the measurement weeks ( 1 to 3 ) and conditions (AC or NC) and the interaction between both and all were included as fixed main effects in the MLR model. Finally, dummy variables representing the three different age groups and those representing the profoundness of the visual impairment were added as fixed effects based on preliminary considerations with regard to their possible influence on play behavior (Hughes et al., 1998, Howes \& Matheson, 1992). Because of the dyad structure it was impossible to extend the random intercept model with random slopes (Kashy \& Kenny, 2011).

To estimate the influence of random intercept variances on the dependent variables, median odds ratios (MOR) were computed using methods described by Merlo et al. (2006). By transforming level-2 variances (of the dyad) into the odds ratio scale comparisons with fixed effects odds ratios become more natural. An odds ratio larger than 1 indicates a larger effect of a characteristic or a certain condition (for example the AC) on play behavior than another characteristic or condition (in this case the NC), whereas an odds ratio smaller than 1 indicates a smaller effect. Comparable to the odds ratio, a MOR notably larger than 1 indicates that the risk of a participant to demonstrate certain play behavior will increase if that participant would be part of a dyad with a higher probability of showing this type of play.

\section{Results}

\subsection{Social play behaviors}

The MLR model produced random intercept variances and odds ratios of main effects for each social play category. Random variances of the models with the best fit are presented in Table 2.

Fig. 3 displays the predicted proportions of time that an average participant in an average dyad spent on each social play behavior. Regardless of condition or measurement week, cooperative play was demonstrated the majority of time and disengaged 
Table 2

Random intercept variance for each social aspect of play.

\begin{tabular}{lcc}
\hline & $\sigma^{2}$ & MOR \\
\hline Solitary & & \\
$\quad$ Dyad level & 2.75 & 4.88 \\
$\quad$ Participant level & 0.01 & 1.10 \\
Parallel & & \\
$\quad$ Dyad level & 1.28 & 2.94 \\
$\quad$ Participant level & 0.07 & 1.29 \\
Cooperative & & \\
$\quad$ Dyad level & 1.28 & 2.94 \\
$\quad$ Participant level & 0.06 & 1.26 \\
Disengagement & & \\
$\quad$ Dyad level & 2.68 & 4.77 \\
Participant level & 0.04 & 1.21 \\
\hline
\end{tabular}

Note. $\sigma^{2}=$ random intercept variance; $\mathrm{MOR}=$ median odds ratio

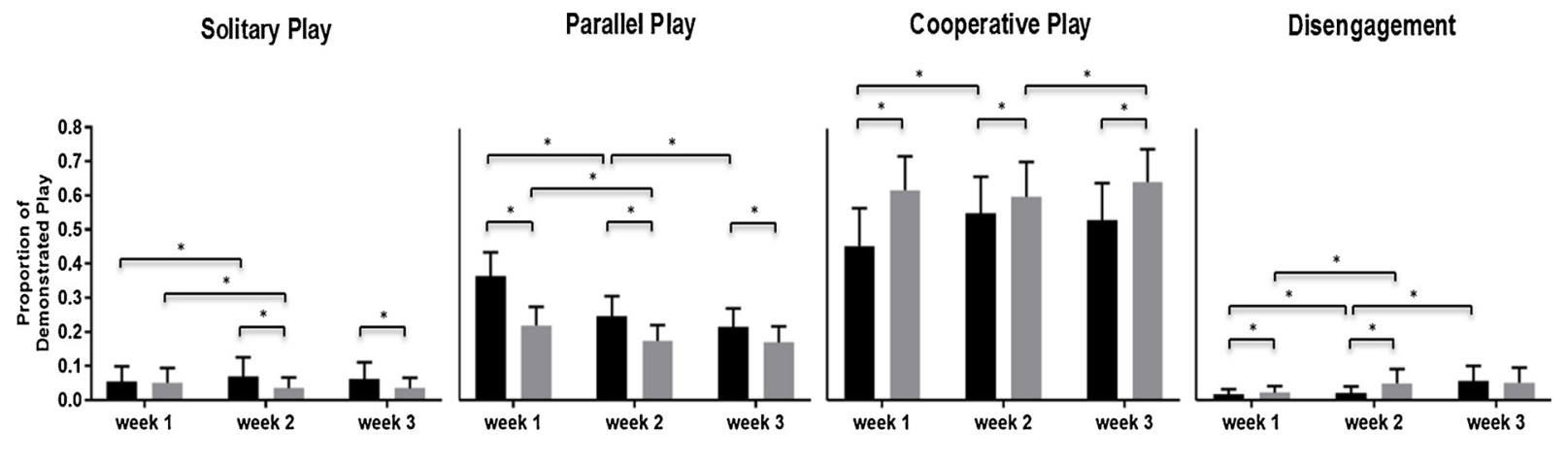

- $\mathrm{AC}=\mathrm{NC}$

Fig. 3. Predicted proportions of social play behaviors for both conditions and three measurement weeks. NB. Error bars reflect 95\% confidence intervals of the mean predicted proportions.

behavior the least, with average proportions of .56 (cooperative play) and .04 (disengagement) respectively.

Closer examination of differences between conditions, presented in Table 3, indicated that participants demonstrated significantly more parallel play in the AC than the NC during all measurement weeks. Disengagement was significantly lower during the AC than the NC for the first two measurement weeks, yet it occurred infrequently compared to the other social play behaviors (i.e., less than $5 \%$ of the time in either of the conditions). Furthermore, predicted proportions of solitary play remained at similar levels (i.e., .05) for both conditions in the first measurement week. In the second and third weeks the chances for solitary play even became significantly lower in the NC, while they remained alike in the AC. The increase in parallel play in the AC compared to the NC mainly led to a decrease in the amount of time spent in cooperative play. Predicted proportions for cooperative play were significantly higher in the NC during all measurement weeks, ranging from .45 to .53 in the AC and from .60 to .64 in the NC. Neither the participant's age nor the profoundness of the visual impairment was significantly associated with the social aspects of play.

\subsection{Cognitive play behaviors}

Sensopathic play, repetitive play and games with rules occurred so infrequently and were demonstrated by such a small number of participants that it was irrelevant to include these play behaviors in further analyses of group means. With regard to the analysis of manipulative play, a distinction was made between manipulative play that included both general manipulative behaviors as well as sound exploration on the one hand (from now on referred to as 'total manipulative play' or TMP), and general manipulative play without sound exploration on the other hand ('basic manipulative play' or BMP). Random intercept variances, median odds ratios and significant fixed effects are presented in Table 4 for each cognitive aspect of play. Similar to results on social play, predicted proportions of cognitive play are shown in Fig. 4 for each condition and measurement week.

From Fig. 4 it can be concluded that an average participant demonstrated both manipulative play and symbolic play most of the time, but that this depended on the condition children played in. In the AC, an average child spent about half of the time on manipulative play in the first session if exploration of the different sounds was included (TMP). Predicted proportions decreased from .47 to .25 over the three measurement weeks, yet TMP was still demonstrated the majority of time compared to the other cognitive aspects of play in the AC. In addition, TMP was significantly higher in AC than in NC during all measurement weeks, suggesting that participants kept on exploring the different sounds (see Table 5 for odds ratios). Second, the actual use of toys in functional and symbolic play occurred significantly less often in the AC than the NC. Although the proportion of symbolic play increased 
Table 3

Odds ratios of social play differences between conditions and measurement weeks.

\begin{tabular}{|c|c|c|c|c|c|c|c|c|c|c|c|c|}
\hline \multirow[b]{3}{*}{ Play categories } & & & \multicolumn{10}{|c|}{ Measurement week } \\
\hline & & & \multicolumn{3}{|l|}{1} & \multicolumn{4}{|l|}{2} & \multicolumn{3}{|l|}{3} \\
\hline & & & \multirow[t]{2}{*}{$\mathrm{AC}$} & \multicolumn{2}{|l|}{ NC } & \multicolumn{2}{|l|}{ AC } & \multicolumn{2}{|l|}{$\mathrm{NC}$} & \multicolumn{2}{|l|}{ AC } & NC \\
\hline \multicolumn{12}{|l|}{ Solitary play } & \\
\hline \multirow[t]{2}{*}{ Week 1} & AC & & & 0.95 & & $1.31^{* *}$ & & - & & 1.14 & & - \\
\hline & NC & & & & & - & & $0.69^{* *}$ & & - & & 0.67 ** \\
\hline \multirow[t]{2}{*}{ Week 2} & AC & & & & & & & $0.49 *$ & & 0.87 & & - \\
\hline & NC & & & & & & & & & - & & 0.98 \\
\hline Week 3 & $\mathrm{AC}$ & & & & & & & & & & & $0.56^{* *}$ \\
\hline \multicolumn{13}{|l|}{ Parallel play } \\
\hline \multirow[t]{2}{*}{ Week 1} & AC & & & $0.49 * *$ & & $0.57 * *$ & & - & & $0.48^{* * *}$ & & - \\
\hline & NC & & & & & - & & $0.75^{*}$ & & - & & $0.73^{* *}$ \\
\hline \multirow[t]{2}{*}{ Week 2} & AC & & & & & & & $0.65^{*}$ & & $0.84^{* * *}$ & & - \\
\hline & NC & & & & & & & & & - & & 0.97 \\
\hline Week 3 & AC & & & & & & & & & & & $0.75^{* *}$ \\
\hline \multicolumn{13}{|c|}{ Cooperative play } \\
\hline \multirow[t]{2}{*}{ Week 1} & AC & & & $1.95^{* * *}$ & & 1.47 ** & & - & & $1.36^{* * *}$ & & - \\
\hline & NC & & & & & - & & 0.92 & & - & & $1.11^{*}$ \\
\hline \multirow[t]{2}{*}{ Week 2} & $\mathrm{AC}$ & & & & & & & $1.22 *$ & & 0.92 & & - \\
\hline & NC & & & & & & & & & - & & $1.20^{* * *}$ \\
\hline Week 3 & $\mathrm{AC}$ & & & & & & & & & & & $1.59^{* *}$ \\
\hline \multicolumn{13}{|l|}{ Disengagement } \\
\hline \multirow[t]{2}{*}{ Week 1} & & AC & & & $1.30^{*}$ & & $1.24^{*}$ & & - & $3.36^{* * *}$ & - & \\
\hline & & NC & & & & & - & & $2.29^{* *}$ & - & $2.40 * *$ & \\
\hline \multirow[t]{2}{*}{ Week 2} & & AC & & & & & & & 1.00 & $2.72^{* * *}$ & - & \\
\hline & & NC & & & & & & & & - & 1.05 & \\
\hline Week 3 & & $\mathrm{AC}$ & & & & & & & & & 1.07 & \\
\hline
\end{tabular}

Note. ${ }^{*} p<.05,{ }^{* *} p<.01$; Y-axis represents the reference variables.

Table 4

Random intercept variance, median odds ratios and significant fixed effects for each cognitive aspect of play.

\begin{tabular}{lccc}
\hline & $\sigma^{2}$ & MOR & Odds ratio \\
\hline Basic manipulative play & & & 1.56 \\
$\quad$ Dyad level & 0.22 & 1.46 & $1.51^{*}$ \\
$\quad$ Participant level & 0.16 & & \\
$\quad$ Severe VI group & & \\
Total manipulative play & & 1.64 \\
$\quad$ Dyad level & 0.27 & 1.46 \\
$\quad$ Participant level & 0.16 & 2.72 \\
Functional play & 1.10 & 1.31 \\
$\quad$ Dyad level & 0.08 & 1.60 \\
$\quad$ Participant level & 0.24 & 1.37 \\
Functional pretense & 0.11 & \\
$\quad$ Dyad level & & & $0.67^{*}$ \\
$\quad$ Participant level & & 3.55 \\
$\quad$ Blind group & & 1.92 \\
$\quad$ Symbolic play & 1.76 & \\
$\quad$ Dyad level & 0.47 &
\end{tabular}

Note. $* p<.05 ; \sigma^{2}=$ random intercept variance; MOR $=$ median odds ratio.

${ }^{\mathrm{a}}$ Reference category $=$ moderate VI group.

significantly from the first to the second week in the AC, it was still lower than in the NC, with proportions of .18 (AC) and .27 (NC) respectively. Finally, the amount of time spent in functional play with pretense did not differ between conditions.

A significant effect of the profoundness of the visual impairment indicated that children with a severe VI demonstrated more BMP than children with a moderate VI, whereas the BMP of children with blindness was not significantly different from the other groups. However, children with blindness did engage in less functional play with pretense than those with a moderate VI. With regard to the effect of age, results showed a trend for 4- to 7-year-olds to demonstrate more sound exploration than 10- to 13-year-olds (OR 1.97, $95 \%$ CI $0.98-3.98, p \quad .059)$. 


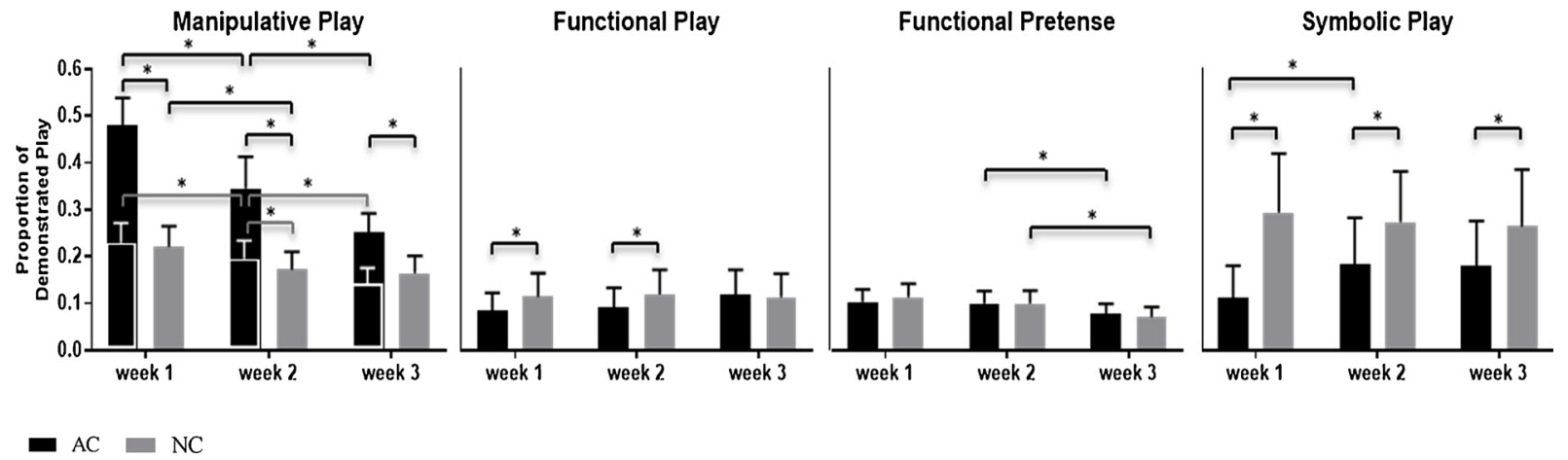

Fig. 4. Predicted proportions of cognitive play behaviors for both conditions and three measurement weeks.

NB. Mean predicted proportions for BMP are projected in white over the black bars of TMP in the augmented condition. Significance for BMP is displayed in grey. Error bars reflect 95\% confidence intervals of mean predicted proportions.

Table 5

Odds ratios of cognitive play differences between conditions and measurement weeks.

\begin{tabular}{|c|c|c|c|c|c|c|c|c|c|c|c|c|c|}
\hline \multirow[b]{3}{*}{ Play categories } & & & \multicolumn{11}{|c|}{ Measurement week } \\
\hline & & & \multicolumn{3}{|l|}{1} & \multicolumn{4}{|l|}{2} & \multicolumn{4}{|l|}{3} \\
\hline & & & \multirow[t]{2}{*}{$\mathrm{AC}$} & \multicolumn{2}{|l|}{$\mathrm{NC}$} & \multicolumn{2}{|l|}{$\mathrm{AC}$} & \multicolumn{2}{|l|}{ NC } & \multicolumn{2}{|l|}{ AC } & \multicolumn{2}{|l|}{ NC } \\
\hline \multicolumn{13}{|c|}{ Basic manipulative play } & \\
\hline \multirow[t]{2}{*}{ Week 1} & AC & & & 0.99 & & $0.81^{* *}$ & & - & & $0.56^{* * *}$ & & - & \\
\hline & NC & & & & & - & & $0.69^{* * *}$ & & - & & $0.63^{* *}$ & \\
\hline \multirow[t]{2}{*}{ Week 2} & $\mathrm{AC}$ & & & & & & & & $0.84^{*}$ & $0.69^{* *}$ & & - & \\
\hline & NC & & & & & & & & & - & & 0.92 & \\
\hline Week 3 & $\mathrm{AC}$ & & & & & & & & & & & 1.12 & \\
\hline \multicolumn{14}{|c|}{ Total manipulative play } \\
\hline \multirow[t]{2}{*}{ Week 1} & $\mathrm{AC}$ & & & $0.31^{* *}$ & & $0.57^{* *}$ & & & - & $0.36^{* * *}$ & & - & \\
\hline & NC & & & & & - & & & $0.73^{* *}$ & - & & $0.69 * *$ & \\
\hline \multirow[t]{2}{*}{ Week 2} & $\mathrm{AC}$ & & & & & & & & 0.39 ** & $0.63^{* *}$ & & - & \\
\hline & NC & & & & & & & & & - & & 0.94 & \\
\hline Week 3 & AC & & & & & & & & & & & $0.59^{* * *}$ & \\
\hline \multicolumn{14}{|l|}{ Functional play } \\
\hline \multirow[t]{2}{*}{ Week 1} & AC & & & $1.41^{* *}$ & & 1.09 & & & - & $1.48^{* *}$ & & & - \\
\hline & NC & & & & & - & & & 1.05 & - & & & 0.99 \\
\hline \multirow[t]{2}{*}{ Week 2} & $\mathrm{AC}$ & & & & & & & & $1.36^{* *}$ & $1.35^{* *}$ & & & - \\
\hline & NC & & & & & & & & & - & & & 0.94 \\
\hline Week 3 & AC & & & & & & & & & & & & 0.94 \\
\hline \multicolumn{14}{|c|}{ Functional pretense } \\
\hline \multirow[t]{2}{*}{ Week 1} & & AC & & & 1.10 & & 0.96 & & - & $0.72^{* *}$ & - & & \\
\hline & & NC & & & & & - & & 0.87 & - & $0.60^{* * *}$ & & \\
\hline \multirow[t]{2}{*}{ Week 2} & & $\mathrm{AC}$ & & & & & & & 1.00 & $0.76^{* * *}$ & & & \\
\hline & & NC & & & & & & & & - & $0.69^{* *}$ & & \\
\hline Week 3 & & AC & & & & & & & & & 0.91 & & \\
\hline \multicolumn{14}{|l|}{ Symbolic play } \\
\hline \multirow[t]{2}{*}{ Week 1} & & AC & & & $3.28^{* * *}$ & & $1.78^{* * *}$ & & - & $1.72^{* *}$ & & - & \\
\hline & & NC & & & & & - & & 0.91 & - & & $0.86^{*}$ & \\
\hline \multirow[t]{2}{*}{ Week 2} & & $\mathrm{AC}$ & & & & & & & $1.67 * *$ & 0.97 & & - & \\
\hline & & $\mathrm{NC}$ & & & & & & & & - & & 0.95 & \\
\hline Week 3 & & AC & & & & & & & & & & $1.65^{\text {** }}$ & \\
\hline
\end{tabular}

NB. ${ }^{*} p<.05,{ }^{* *} p<.01, \mathrm{Y}$-axis represents the reference variables.

\section{Discussion}

The aim of this study was to investigate whether toys with sound augmentation would facilitate social and cognitive play in dyads of school-aged children with visual impairments (VIs). The expectation that playing with an augmented toy would facilitate social play was only partly supported. In line with our main hypothesis, children with VIs showed parallel play more often when sound augmentation was available, even after three opportunities to play with the augmented toy. This indicates that sounds indeed captured the children's attention and facilitated joint attention and awareness of a peer's actions during play. Parallel play is regarded 
as an important bridge between different social aspects of play and essential for peer group entry (Dodge, Schlundt, Schocken, \& Delugach, 1983; Robinson, Anderson, Porter, Hart, \& Wouden-Miller, 2003). In this respect, our finding that more parallel play occurred in the augmented condition would suggest that sound augmentation provided participants with possibilities to engage in peer play. But results regarding cooperative play indicate otherwise. Cooperative play was demonstrated significantly more often when the participants used the non-augmented toy and this was true for all play sessions. Although the time spent in cooperative play did increase when children played with the augmented toy for a second time, it remained lower than with the non-augmented toy during all play sessions. Since cooperative play is the most complex aspect of social play (Howes \& Matheson, 1992; Parten, 1932) and essential for the development of social skills and friendships (Lillard, 2001), these findings do not confirm that sound augmentation facilitated social play in children with VIs. Furthermore, the sound augmentation did not have an effect on the amount of time that participants spent in solitary play when they first used the augmented castle. The second session with the augmented castle even led to a slight increase of solitary play, whereas it decreased when participants used the non-augmented castle. Yet, the participant group demonstrated solitary play very infrequently in either condition, as was the case for disengaged behavior.

Playing with the augmented castle also did not have the hypothesized effects on the cognitive play of the participants. Whereas repeated use of the augmented toy was expected to facilitate the integration of objects in functional and symbolic play, it mainly facilitated manipulative play. When participants used the augmented toy for the first time, they spent almost half of their time in manipulative play, predominantly due to sound exploration. During the second and third play session with the augmented toy, children still showed manipulative play for the majority of time and more often than with the non-augmented toy. In contrast, participants engaged in symbolic play most of the time during all three sessions with the non-augmented castle. This increase in manipulative play during the augmented condition led to a decrease of the amount of time that children with VIs spent in both symbolic as well as functional play compared to the non-augmented condition. Surprisingly, sound augmentation did not have any effect on the demonstration of functional play with pretense, where children add simple pretend acts to the functional use of toys. According to Lewis, Norgate et al. (2000), children with a severe VI have difficulties with this type of play in particular, emphasizing the need to find ways for them to discover how a variety of objects can be involved in pretend acts. Results of the present study indeed indicated that functional play with pretense was especially difficult for participants with blindness, since they demonstrated this type of play significantly less often than participants with a moderate VI. Unfortunately, our findings suggest that increasing the awareness of the multiplicity of play figures does not necessarily increase the time that children with VIs spend in functional play (with pretense) or symbolic play. In conclusion, it appears that sound augmentation of play materials can facilitate shared attention and explorative behavior in children with VIs, but can also interfere with the children's own verbalizations and pretend acts during peer play.

A first reason why the sound augmentation interfered with cooperative and symbolic play in particular is that the type of sounds might not have been adequate to facilitate these play behaviors in children with VIs. The sounds did not explicitly encourage the children to cooperate, but merely identified characters or gave suggestions for fantasy play (e.g., 'A dragon is attacking the castle'). Although the play propositions were expected to facilitate symbolic play, they often interfered with the storylines that participants invented themselves. This most likely had to do with the fact that participants in our study had multiple opportunities to play with the toys and to extend the storylines they made-up, whereas the sounds remained the same during all play sessions.

The augmented knights castle did facilitate social play in children with autism, who often experience similar difficulties as children with VIs during peer play and symbolic play (Farr et al., 2012; Mundy \& Sigman, 2015). Even though the children with autism had only one opportunity to use the augmented castle, they demonstrated significantly less solitary play and comparable amounts of parallel and cooperative play as with the non-augmented castle. An important difference regarding the design of both studies is that children in our study participated in dyads, whereas children in the study of Farr et al. (2012) played in triads. In a triad it is more likely that sound production draws someone's attention and stimulates peer interaction than in a dyad: if one child is focused on the exploration of the different sounds, the two others can discuss what they just heard. But differences between both participant groups with regard to the underlying mechanisms that cause autism or visual impairments are also likely to play a role (Andrews \& Wyver, 2005). Whereas children with autism often experience innate inabilities to engage in social interaction in general, most children with VIs do have the ability and need for social interaction, but conditions for interaction are compromised because of the lack of sight (Cass, 1998; Warren, 1994). In this respect, sound augmentation might have a different effect on play of both groups of children and this remains a topic for further research.

A closer look at the time that participants spent on social play with the non-augmented toy raises the question whether it was possible to facilitate social play in the first place. On average, the participants already spent more than half of their time playing cooperatively, whereas solitary play and disengagement practically did not occur. This finding is rather surprising, given the fact that other studies described observations that led to conclusions in the opposite direction for children with VIs (Celeste, 2006; Erwin, 1993; Skellenger et al., 1997). The fact that most participants in our study had a moderate VI might have played a role, as social difficulties are reported more often in children with blindness (Hughes et al., 1998; Troster \& Brambring, 1994). Since our participants played in dyads, the children with blindness mostly participated together with a peer with a moderate VI that could explain more about the toys or how to use them.

However, even though the social play behavior of children with VIs as a group appeared to be very adequate, large individual differences were observed between participants. Some dyads demonstrated cooperative symbolic play almost all of the time whereas others manipulated toys without focusing on their playmate throughout the play session. Yet the social aspects of play did not differ as a function of the profoundness of the visual impairment. These findings support the claim that children with VIs might be at risk for peer play difficulties as a group, but that factors other than the visual impairment itself are more important predictors of persistent social play difficulties (Lewis, Norgate et al., 2000; Warren, 1994). 


\subsection{Limitations and future research}

A first limitation of the present study is that the observational methods might have led to an underestimation of the social interaction between children. Some children would demonstrate four different types of social play within 10 seconds, making it too difficult to reach sufficient inter-rater reliability when using event sampling. Therefore, interval sampling was used, although this simplified the data. Secondly, participants were not included based on their visual acuity but based on their attendance of special schools for the visually impaired and blind. This resulted in four children having more than $30 \%$ remaining sight due to optical correction, which might have affected their play and that of their playmate to some extent. Furthermore, the mean age of our participants was relatively high, mainly because 4- to 7-year-olds were underrepresented compared to the other age groups in the present sample. The amount of 4- to 7-year-old children attending special education at the time of data collection appeared to be smaller than expected, as most children with VIs in this age group were actually in regular education. Although no significant effects of age on play behavior were found, this might be due to the small group of 4- to 7-year-old participants. Since symbolic play delays have mostly been reported in young children with VIs (Bishop et al., 2005; Hughes et al., 1998), augmented toys could be helpful for this group in particular, suggesting the need for further research. Yet our sample is an adequate representation of the Dutch population of children with VIs in special education and so far, little studies focused on play behavior in the elementary school ages.

Several other suggestions for future research are proposed. First of all, it would be interesting to investigate whether increasing the flexibility of sound augmentation to the dynamic nature of children's play can facilitate the use of sounds in more elaborate symbolic play. The sounds involving play propositions often interfered with the storylines that participants invented when using the augmented toy repeatedly. Some children tried to avoid these play propositions as a result, only wanting to produce sounds that identified characters (such as the dragon roaring). In their study, Farr et al. (2012) added configurable elements to the augmented knights' castle, such that children could record their own sounds for play figures. The configurability led to an increase in the amount of transitions towards cooperative play compared to the 'normal' augmented castle and might also be more supportive for symbolic play. Second of all, it would be relevant to study the effect of sound augmentation on play and interaction between sighted children and those with VIs as well. Even though a significant group of children with VIs attend special education in the Netherlands, most of them attend regular education (Smeets \& de Boer, 2017). Former research shows that levels of peer interaction differed between children with VIs attending special- or regular education (Guralnick, Connor, Hammond, Gottman, \& Kinnish, 1996), or if children with VIs played with sighted peers versus other children with VIs (D'Allura, 2002). In addition, social participation difficulties during free play situations have been reported for children with VIs in regular education, underlining the importance of adequate support during peer interaction in this setting (Hestenes \& Carroll, 2000). Further research is needed to investigate if augmented toys can facilitate peer play in this context. Finally, our results indicate that characteristics other than the visual impairment itself might be more important contributors to social play difficulties in children with VIs. Several studies reported that verbal abilities, social competence and the manifestation of autistic features predicted the complexity of symbolic play in children with blindness or a severe VI (Bishop et al., 2005; Lewis, Norgate et al., 2000; Rettig, 1994). Further research is needed to comprehend which factors increase the risk for persistent peer play difficulties in children with VIs and whether sound augmentation of toys might be useful for these children after all.

\subsection{Conclusions}

In sum, the sound augmentation stimulated joint attention during parallel play and explorative play behaviors in children with VIs as a group. Yet this increase in joint attention did not lead to more cooperative play between children when they used the augmented toy multiple times. The sounds seemed to interfere with the children's own verbalizations and with the dynamic nature of their symbolic play. However, large individual differences were present between children that could not be explained by the profoundness of the visual impairment.

\section{Funding roles}

This work was supported by the Dutch Organization for Health Research and Development (ZonMW) [dossier number: 60-0063598-140]. The funding source had no involvement in the collection, analysis and interpretation of data, in the writing of the report, or in the decision to submit the article for publication.

\section{Conflicts of interest}

None.

\section{Acknowledgements}

First of all, the authors wish to thank all the children and parents that participated in this study. Second of all, we would like to thank the staff of Royal Dutch Visio and Bartiméus for collaborating. Our gratitude goes out to Stichting Inzicht and the Dutch Organization for Health Research and Development (ZonMW) for funding the current project. 


\section{References}

Andrews, R., \& Wyver, S. (2005). Autistic tendencies: Are there different pathways for blindness and Autism Spectrum Disorder? British Journal of Visual Impairment, 23(2), 52-57.

Astington, J. W., \& Jenkins, J. M. (1995). Theory of mind development and social understanding. Cognition \& Emotion, 9(2-3), 151-165.

Belsky, J., \& Most, R. K. (1981). From exploration to play: A cross-sectional study of infant free play behavior. Developmental Psychology, 17(5), 630-639.

Bergen, D. (2002). The role of pretend play in children's cognitive development. Early Childhood Research \& Practice, 4(1), Retrieved from https:/files.eric.ed.gov/ fulltext/ED464763.pdf.

Bishop, M., Hobson, R. P., \& Lee, A. (2005). Symbolic play in congenitally blind children. Development and Psychopathology, 17(02), 447-465.

Brown, R., Hobson, R. P., Lee, A., \& Stevenson, J. (1997). Are there "autistic-like" features in congenitally blind children? Journal of Child Psychology and Psychiatry, 38(6), 693-703.

Cass, H. (1998). Visual impairment and autism: Current questions and future research. Autism, 2(2), 117-138.

Celeste, M. (2006). Play behaviors and social interactions of a child who is blind: In theory and practice. Journal of Visual Impairment \& Blindness, 100(2), 75-90.

Cohen, J. (1968). Weighted kappa: Nominal scale agreement provision for scaled disagreement or partial credit. Psychological Bulletin, 70(4), $213-220$.

D'Allura, T. (2002). Enhancing the social interaction skills of preschoolers with visual impairments. Journal of Visual Impairment \& Blindness, 96(08), 576-584.

Dodge, K. A., Schlundt, D. C., Schocken, I., \& Delugach, J. D. (1983). Social competence and children's sociometric status: The role of peer group entry strategies. Merrill-Palmer Quarterly, 29(3), 309-336.

Doyle, A. B., \& Connolly, J. (1989). Negotiation and enactment in social pretend play: Relations to social acceptance and social cognition. Early Childhood Research Quarterly, 4(3), 289-302.

Doyle, A. B., Doehring, P., Tessier, O., de Lorimier, S., \& Shapiro, S. (1992). Transitions in children's play: A sequential analysis of states preceding and following social pretense. Developmental Psychology, 28(1), 137-144.

Elias, C. L., \& Berk, L. E. (2002). Self-regulation in young children: Is there a role for sociodramatic play? Early Childhood Research Quarterly, 17(2), 216-238.

Erwin, E. J. (1993). Social participation of young children with visual impairments in specialized and integrated environments. Journal of Visual Impairment, 87(5), $138-142$.

Farr, W., Yuill, N., \& Hinske, S. (2012). An augmented toy and social interaction in children with autism. International Journal of Arts and Technology, 5(2-4), 104-125.

Farr, W., Yuill, N., \& Raffle, H. (2010). Social benefits of a tangible user interface for children with autistic spectrum conditions. Autism, 14(3), $237-252$.

Fraiberg, S. (1977). Insights from the blind: Comparative studies of blind and sighted infants. New York: Basic Books (AZ).

Galati, D., Miceli, R., \& Sini, B. (2001). Judging and coding facial expression of emotions in congenitally blind children. International Journal of Behavioral Development, 25(3), 268-278.

Guralnick, M. J., Connor, R. T., \& Hammond, M. (1995). Parent perspectives of peer relationships and friendships in integrated and specialized programs. American Journal on Mental Retardation, 99(5), 457-475.

Guralnick, M. J., Connor, R. T., Hammond, M., Gottman, J. M., \& Kinnish, K. (1996). Immediate effects of mainstreamed settings on the social interactions and social integration of preschool children. American Journal on Mental Retardation, 100(4), 359-377.

Hinske, S., Lampe, M., Yuill, N., Price, S., \& Langheinrich, M. (2009). Kingdom of the Knights: evaluation of a seamlessly augmented toy environment for playful learning. Proceedings of the 8th International Conference on Interaction Design and Children, 202-205.

Hestenes, L. L., \& Carroll, D. E. (2000). The play interactions of young children with and without disabilities: Individual and environmental influences. Early childhood research quarterly, 15(2), 229-246.

Howes, C., \& Matheson, C. C. (1992). Sequences in the development of competent play with peers: Social and social pretend play. Developmental Psychology, 28(5), 961-974.

Howes, C., Unger, O., \& Matheson, C. C. (1992). The collaborative construction of pretend: Social pretend play functions. Albany: SUNY Press.

Hughes, M., Dote-Kwan, J., \& Dolendo, J. (1998). A close look at the cognitive play of preschoolers with visual impairments in the home. Exceptional Children, 64(4), 451-462.

Huurre, T. M., Komulainen, E. J., \& Aro, H. M. (1996). Social networks and social support among adolescents with visual impairments. Journal of Social Medicine, 33, $113-120$.

ICD-10 (2015). Retrieved from http://apps.who.int/classifications/icd10/browse/2015/en\#/H54.

Kashy, D. A., \& Kenny, D. A. (2011). Dyadic data analysis using multilevel modeling. Handbook of advanced multilevel analysis. London: Routledge343-378.

Kef, S., \& Deković, M. (2004). The role of parental and peer support in adolescents well-being: a comparison of adolescents with and without a visual impairment. Journal of Adolescence, 27(4), 453-466.

Lampe, M., \& Hinske, S. (2007). The augmented knight's castle-integrating mobile and pervasive computing technologies into traditional toy environments. Concepts and technologies for Pervasive Games-A Reader for Pervasive Gaming Research, 1, 41-66.

Leonhardt, M. (1990). Stereotypes: A preliminary report on mannerisms and blindisms. Journal of Visual Impairment \& Blindness, 84(5), 216-218.

Lewis, V., Boucher, J., Lupton, L., \& Watson, S. (2000). Relationships between symbolic play, functional play, verbal and non-verbal ability in young children. International Journal of Language \& Communication Disorders, 35(1), 117-127.

Lewis, V., Norgate, S., Collis, G., \& Reynolds, R. (2000). The consequences of visual impairment for children's symbolic and functional play. Journal of Developmental Psychology, 18(3), 449-464.

Lifter, K., Foster-Sanda, S., Arzamarski, C., Briesch, J., \& McClure, E. (2011). Overview of play: Its uses and importance in early intervention/early childhood special education. Infants \& Young Children, 24(3), 225-245.

Lifter, K., Mason, E. J., \& Barton, E. E. (2011). Children's play: Where we have been and where we could go. Journal of Early Intervention, 33(4), $281-297$.

Lillard, A. S. (1998). Playing with a theory of mind. In O. Saracho, \& B. Spodek (Eds.). Multiple Perspectives on Play in Early Childhood Education (pp. 11-33). Albany: SUNY Press.

Lillard, A. S. (2001). Pretend play as twin earth: A social-cognitive analysis. Developmental Review, 21(4), 495-531.

Lillard, A. S., Lerner, M. D., Hopkins, E. J., Dore, R. A., Smith, E. D., \& Palmquist, C. M. (2013). The impact of pretend play on children's development: A review of the evidence. Psychological Bulletin, 139(1), 1-34.

Merlo, J., Chaix, B., Ohlsson, H., Beckman, A., Johnell, K., Hjerpe, P., et al. (2006). A brief conceptual tutorial of multilevel analysis in social epidemiology: using measures of clustering in multilevel logistic regression to investigate contextual phenomena. Journal of Epidemiology \& Community Health, 60(4), $290-297$.

Mundy, P., \& Sigman, M. (1989). The theoretical implications of joint-attention deficits in autism. Development and Psychopathology, 1(3), $173-183$.

Mundy, P., \& Sigman, M. (2015). Joint attention, social competence, and developmental psychopathology. Developmental Psychopathology: Volume One: Theory and Method, 293-332.

Mundy, P., Sigman, M., \& Kasari, C. (1990). A longitudinal study of joint attention and language development in autistic children. Journal of Autism and Developmental Disorders, 20(1), 115-128.

Parten, M. B. (1932). Social participation among pre-school children. The Journal of Abnormal and Social Psychology, 27(3), 243-269.

Pellegrini, A. D. (1982). Development of preschoolers' social-cognitive play behaviors. Perceptual and Motor Skills, 55(3), 1109-1110.

Perez-Pereira, M., \& Conti-Ramsden, G. (2013). Language Development and Social Interaction in Blind Children. Psychology Press.

Pizzo, L., \& Bruce, S. M. (2010). Language and play in students with multiple disabilities and visual impairments or deaf-blindness. Journal of Visual Impairment \& Blindness, 104(5), 287-297.

Preisler, G. M. (1993). A descriptive study of blind children in nurseries with sighted children. Child: Care, Health and Development, 19(5), $295-315$.

Recchia, S. L. (1997). Play and concept development in infants and young children with severe visual impairments: A constructivist view. Journal of Visual Impairment \& Blindness, 91(4), 401-406.

Rettig, M. (1994). The play of young children with visual impairments: Characteristics and interventions. Journal of Visual Impairment \& Blindness, 88(5), 410-420. 
Robb, S. L. (2003). Music interventions and group participation skills of preschoolers with visual impairments: Raising questions about music, arousal, and attention. Journal of Music Therapy, 40(4), 266-282.

Robinson, C. C., Anderson, G. T., Porter, C. L., Hart, C. H., \& Wouden-Miller, M. (2003). Sequential transition patterns of preschoolers' social interactions during childinitiated play: Is parallel-aware play a bidirectional bridge to other play states? Early Childhood Research Quarterly, 18(1), 3-21.

Roch-Levecq, A.-C. (2006). Production of basic emotions by children with congenital blindness: Evidence for the embodiment of theory of mind. British Journal of Developmental Psychology, 24(3), 507-528.

Roe, J., \& Webster, A. (2002). Children with visual impairments: Social interaction, language and learning. London: Routledge.

Rogers, S. J., \& Puchalski, C. B. (1984). Development of symbolic play in visually impaired young children. Topics in Early Childhood Special Education, 3(4), 57-63.

Rubin, K. H., Maioni, T. L., \& Hornung, M. (1976). Free Play Behaviors in Middle- and Lower-Class Preschoolers: Parten and Piaget Revisited. Child Development, 47(2), 414-419.

Sacks, S., \& Kekelis, L. (1992). The development of social skills by blind and visually impaired students: Exploratory studies and strategies. American Foundation for the Blind, New York: AFB Press.

Skellenger, A. C., Rosenblum, L. P., \& Jager, B. K. (1997). Behaviors of preschoolers with visual impairments in indoor play settings. Journal of Visual Impairment \& Blindness, 91(6), 519-530.

Sleeuwenhoek, H. C., Boter, R. D., \& Vermeer, A. (1995). Perceptual-motor performance and the social development of visually impaired children. Journal of Visual Impairment \& Blindness, 89(4), 359-367.

Smeets, E., \& de Boer, A. (2017). Deelonderzoekplan Evaluatie passend onderwijs. Thematische gevalsstudie: het onderwijs aan en de ondersteuning van leerlingen met een visuele of auditieve beperking en/of taalontwikkelingsstoornis. Retrieved fromhttp://evaluatiepassendonderwijs.nl/onderzoek/onderzoeksplannen/thematischecasestudie-leerlingen-visuele-auditieve-beperking-enof-taalontwikkelingsstoornis/.

Sommet, N., \& Morselli, D. (2017). Keep calm and learn multilevel logistic modeling: A simplified three-step procedure using Stata, R, Mplus, and SPSS. International Review of Social Psychology, 30(1), 203-218.

Troster, H., \& Brambring, M. (1994). The play behavior and play materials of blind and sighted infants and preschoolers. Journal of Visual Impairment, 88(5), 421-432.

Van den Broek, E. G. C., Moleman, Y. H., \& Hellendoorn, J. (2005). Spel ontwikkelingsschaal voor slechtziende en blinde kinderen. Huizen: Koninklijke Visio.

Warren, D. H. (1994). Blindness and children: An individual differences approach. Cambridge University Press.

Wolfberg, P. J., \& Schuler, A. L. (1993). Integrated play groups: A model for promoting the social and cognitive dimensions of play in children with autism. Journal of Autism and Developmental Disorders, 23(3), 467-489.

Youngblade, L. M., \& Dunn, J. (1995). Individual differences in young children's pretend play with mother and sibling: Links to relationships and understanding of other people's feelings and beliefs. Child Development, 66(5), 1472-1492. 